\title{
THE EFFECTS OF POLARIZING CURRENTS ON THE CONSOLIDATION OF LEARNING
}

\author{
D. J. ALBERT* \\ Mental Health Research Institute, The University of Michigan, Ann Arbor, Michigan, U.S.A.
}

(Received 24 August 1965)

\begin{abstract}
The consolidation of an interhemispherically transferred avoidance response was studied. The conditions for consolidation seem to be easily altered by polarizing currents. A pulsating surface-positive current applied to the medial cortex speeds consolidation and, when applied following the disturbance of consolidation by spreading cortical depression or cathodal polarization, restarts the interrupted process. These findings suggest that anodal polarization can augment the conditions required for consolidation, and, when applied following the disturbance of these conditions, can reestablish them. Other experiments suggested that there is a special information holding mechanism mediating recall during the consolidation period that is distinct from the holding mechanism serving as a template for the formation of the permanent retention system. Finally, a new way of estimating the length of the consolidation period has been investigated and the results suggest that the time required for consolidation is longer than that found in other ways.
\end{abstract}

\section{INTRODUCTION}

IN A previous paper [2] evidence has been considered which supports the idea that electrical potentials are involved in the consolidation of learning. Part of this evidence [10,11] shows that pulsating surface-positive currents applied to the cortex during acquisition can, with some kinds of learning, lengthen the period of retention from several hours to a period of days. This suggests that the effect of the surface-positive current is to initiate the consolidation of the learning. Another relevant finding is that pulsating surface-negative current, which should have many effects opposite to those of surface-positive current, blocks retention when applied during the consolidation period [2].

The present experiments pursue the implications of these findings. In the first experiment, anodal polarization is applied to the cortex following acquisition and the effect is an acceleration of the consolidation process. In the second experiment, anodal polarization applied following the interruption of consolidation is found to reestablish the disturbed process. The final experiments make use of these findings and of the disrupting effect on consolidation by cathodal current to consider some of the mechanisms involved in the consolidation process.

The preparation used in these experiments is an interhemispherically transferred avoidance response. The animal acquires an avoidance response in one hemisphere while the other is nonfunctional with cortical spreading depression. The animal is then given a transfer trial with both hemispheres functional to cause the learning to transfer to the untrained hemisphere. The consolidation of the transferred learning in the receiving, or untrained, hemisphere is then studied.

* Postdoctoral Fellow. This work was supported by a grant to the Mental Health Research Institute (NIH M7417-04). 
The advantages of this preparation are that the transfer of the learning from the untrained hemisphere is rapid (about $3 \mathrm{~min}$ ), while consolidation takes considerably longer, at least $2 \mathrm{hr}$. Also, it is already known that consolidation in the receiving hemisphere can be blocked by small surface-negative currents applied to the medial region of the cortex [2].

\section{METHOD}

The experiments all follow a single schedule with but minor variations to accommodate the different ways of interfering with consolidation. The subjects were naive, male rats weighing 200-250 g from Spartan Research Animals (albino) and Maxfield Animal Supply (hooded). Polyethylene cannulas for starting spreading depression were first implanted in the antero-lateral parietal bone over each hemisphere. On the following day (day 1), the animals were trained on an avoidance task while one hemisphere had cortical spreading depression.

On day 2, the animals were given a transfer trial with both hemispheres functional. This causes the learning to transfer from the trained to the untrained hemisphere. The treatment of the animals, in general, differed only at this point when spreading depression or cortical polarization was used to alter the consolidation process in the hemisphere receiving the transferred learning.

On day 3, the trained hemisphere was depressed and the animals were tested for retention of the transferred learning. If the interference with consolidation abolished retention the animals should take as many trials to learn as in the original training, but if there is retention, they should learn in fewer trials. Five to eight animals were usually sufficient to establish reliable estimates of the amount of retention.

A detailed description of this preparation and the methods of interfering with consolidation has been presented previously [2] and will be described only generally here. The avoidance apparatus was a box $(10 \times 36 \times 18$ in. deep $)$ with white and black halves separated by a sliding partition. The animal was first placed in the black side and then removed to the white side. If the animal returned to the black side within $5 \mathrm{sec}$, the trial was counted as an avoidance; if not, the animal was shocked intermittantly (400 V through 1.2 M $\Omega$ ) until it escaped to the black side. The animal was trained in one session to a criterion of 9 avoidances in 10 successive trials. The intertrial interval was $1 \mathrm{~min}$.

Approximately 25 per cent of the animals operated were discarded in the course of training and retraining in the avoidance apparatus. The major reasons for discarding animals were: too rapid (less than 10 trials) or too slow (more than 30 trials) first learning; development of localized motor seizures during training or retraining which interfered with performance.

Unilateral spreading depression was started and maintained during training and testing by 12 per cent potassium chloride $(\mathrm{KCl})$ placed in the cannula over one cortex. The $\mathrm{KCl}$ was left in the cannula for as long as spreading depression was wanted on the cortex and then removed by flushing the cannula with sterile 0.9 per cent saline. The presence of spreading depression was verified by noting a hypesthesia of the body contralateral to the depressed hemisphere.

The same method of starting spreading depression was used for interfering with consolidation. For this purpose, the duration of spreading depression is important and it is estimated as the interval between the time the hypesthesia is first observed until the $\mathrm{KCl}$ is flushed from the cannula. 
The anodal or cathodal current used to interfere with consolidation consisted of a $12 \mu \mathrm{A}$ current passed from an electrode above the medial cortex (see [2] Fig. 5), through the animal, and out a silver wire lead on the animal's back. The electrode on the head was of silver-silver chloride and was held by a polyethylene cannula. Current from this electrode did not go directly to the cortical tissue, but first went through the 0.9 per cent saline in the cannula and then through the dura mater where the immediate area of polarization was $1.5 \mathrm{~mm}^{2}$, the area of the cannula.

A pulsating wave form was used for both anodal and cathodal polarization unless otherwise stated. It consisted of a 15 -sec ramp rise to peak current $\left(8.0 \mu \mathrm{A} / \mathrm{mm}^{2}\right)$ and maintained at that level for $45 \mathrm{sec}$, then a 15 -sec ramp decrease to 0 current and maintained for $45 \mathrm{sec}$. The current was modulated manually. The current source was a $90 \mathrm{~V}$ battery in series with a potentiometer and high resistance.

\section{RESULTS}

The description of these experiments will use the following terminology. The trained, or transmitting, hemisphere is the one that is normal during the first training; it is the hemisphere that records the learning and later transmits it to the other during the transfer trial. The untrained, or receiving, hemisphere is depressed during the first training and later receives the transferred learning.

\subsection{The rate of the consolidation process}

It is known from earlier work [2] that a period of spreading depression which is not long enough to impair retention may still slow the process of consolidation. Since the disturbing effects of spreading depression were suggested to be the result of cortical potential disturbances similar to that caused by passing a surface-negative current through the cortex, it seemed possible that one effect of surface-positive polarization might be to create the opposite effect, to speed consolidation. This increase in rate could be observed as a decrease in the time following transfer (learning) when a disturbing agent can be introduced and still abolish retention.

The animals were trained with one hemisphere depressed and then given a transfer trial the following day. (In this and subsequent experiments, the number of animals in each group is given in the table or figure containing the results.) Surface-positive polarization of the medial cortex of the receiving hemisphere began 5 min later and continued for 16 min. A 30-min period of spreading depression (which is known to abolish retention when started as long as 2 hours after transfer [2]) was used to interfere with consolidation. It began at varying times after anodal polarization ended. The following day, spreading depression was started on the trained hemisphere and the animals were tested for retention of the transferred learning.

The results are clear (Table 1). In the animals receiving anodal polarization, spreading depression did not abolish retention even when started at $30 \mathrm{~min}$ after transfer, which was about the earliest it could be started. In the 30-min group, relearning required 7.6 trials, a significant $(P<0.05$; all statistics are two-tailed rank tests) savings over the original learning and a $1 \mathrm{hr}$ group took 3.4 trials, also significantly better than the original learning. Since spreading depression did not interfere with retention even at the earliest time, a control group with no anodal polarization was given the period of sprcading depression at $1 \mathrm{hr}$. With this group, relearning was not significantly faster than the original learning (11.3 trials). 
Several additional control groups were run to further clarify the interpretation of these results. To control for the possibility that the effect of the anodal polarization was not restricted to the medial cortex, where other evidence suggests the consolidation of this learning occurs [2], a group of animals was given the surface-positive polarization in the anterior region prior to spreading depression. Relearning required 12.9 trials, slightly more than the control group without anodal polarization. To control for experimenter bias as a source of error, the speeding effect of anodal polarization was repeated blind. The experimental group was given the 16-min period of anodal polarization beginning $5 \mathrm{~min}$ after transfer and then a 16-min period of cathodal polarization (previously shown to abolish retention [2], at $30 \mathrm{~min}$; the control group received only the cathodal polarization at $30 \mathrm{~min}$. The results were the same: the experimental group showed retention ( 8.0 trials) while the control group did not (13.4 trials; $P<0.05)$. (There were no differences between groups in the original learning scores in this or succeeding experiments.)

Table 1. The effect of anodal polarization on the rate of consolidation. Surface-positive polarization of the medial or anterior cortex began 5 min after the transfer trial and was followed by spreading depression or medial cathodal polarization

\begin{tabular}{lccc}
\hline & \multicolumn{2}{c}{ Mean trials to learn } \\
\cline { 2 - 4 } Treatment & $\mathrm{N}$ & $\begin{array}{c}\text { First } \\
\text { learning }\end{array}$ & $\begin{array}{c}\text { Learning with } \\
\text { untrained hemisphere }\end{array}$ \\
\hline $\begin{array}{l}\text { Medial polarization, spreading } \\
\text { depression at } 30 \text { min }\end{array}$ & 7 & $14.7 \pm 4.0$ & $7.6 \pm 4.7^{*}$ \\
$\begin{array}{l}\text { Medial polarization, spreading } \\
\text { depression at } 1 \text { hr }\end{array}$ & 7 & $12.0 \pm 2.0$ & $4.0 \pm 2.6^{*}$ \\
$\begin{array}{l}\text { Anterior polarization, spreading } \\
\text { depression at } 30 \text { min }\end{array}$ & 7 & $12.6 \pm 4.0$ & $12.9 \pm 2.9$ \\
$\begin{array}{l}\text { No polarization, spreading } \\
\text { depression at } 1 \text { hr }\end{array}$ & 7 & $13.1 \pm 2.2$ & $11.3 \pm 4.4$ \\
$\begin{array}{l}\text { Medial anodal polarization, } \\
\text { cathodal polarization at } 30 \text { min }\end{array}$ & 6 & $17.7 \pm 3.5$ & $13.4 \pm 3.4$ \\
$\begin{array}{l}\text { No anodal polarization, cathodal } \\
\text { polarization at } 30 \text { min }\end{array}$ & 8 & $14.6 \pm 1.3$ & \\
\hline
\end{tabular}

* Significantly different from first learning $(P<0.05)$.

$\uparrow$ Groups run blind.

These results show that a surface-positive polarizing current can greatly speed consolidation, though whether this is due to an increase in rate which is maintained or to a rapid addition of an increment with each pulsation of current, or both, is not clear.

The finding that anodal polarization has the predicted speeding effect on consolidation suggests that it may be altering in an opposite way the same process that cathodal polarization disturbs. This means that the current parameters which were found most effective in disrupting consolidation with cathodal current [2], a pulsating wave form and a long duration, should also be optimal for the anodal effect. The importance of these parameters in the speeding of consolidation was tested in two additional experiments. In the first 
experiment, two wave forms, a pulsating and a constant current, were compared. The increase in rate of consolidation was again measured by observing a decrease in the time required for consolidation.

About 5 min following the transfer trial, the pulsating surfacc-positive current was started in one group and a constant current of the same intensity in the other; in both groups, the duration of polarization was $16 \mathrm{~min}$. At $1 \mathrm{hr}$ following transfer, the consolidation process was disturbed by a $30 \mathrm{~min}$ period of spreading depression. The animals were tested for retention $24 \mathrm{hr}$ later.

The effect of the wave form of the anodal current is seen in Table 2. The group given the pulsating current prior to spreading depression retained the learning ( 3.7 trials) but the group with the constant current did not $(11.9$ trials, $P<0.05)$.

Table 2. The effect of two wave forms of anodal polarization on the rate of consolidation. Anodal polarization was given at 5 min after transfer and spreading depression at $1 \mathrm{hr}$ (when it normally blocks consolidation)

\begin{tabular}{lccc}
\hline & & \multicolumn{2}{c}{ Mean trials to learn } \\
\cline { 3 - 4 } Current wave form & $N$ & $\begin{array}{c}\text { First } \\
\text { learning }\end{array}$ & $\begin{array}{c}\text { Learning with } \\
\text { untrained hemisphere }\end{array}$ \\
\hline Constant & 6 & $13.8 \pm 6.6$ & $11.9 \pm 4.1$ \\
Pulsating & 6 & $14.0 \pm 2.6$ & $3.7 \pm 2.4^{*}$ \\
\hline
\end{tabular}

* Significantly different from first learning $(P<0.05)$.

The relation between duration of anodal current and increase in speed of consolidation was examined in a second experiment. The increase in speed was again observed by measuring the shortening of the interval during which consolidation would be disrupted, but the disturbance used to interrupt consolidation was surface-negative polarization instead of spreading depression. Its wave form and intensity were the same as that of the anodal current.

Five minutes following the transfer trial, a $0-, 8-$, or $16-$ min period of pulsating surfacepositive polarization was applied to the medial cortex of the receiving hemisphere; then at varying times afterward, a 16-min period of cathodal polarization was started. The animals were tested for retention $24 \mathrm{hr}$ later.

The amount of anodal polarization clearly affects the extent to which consolidation is speeded (Fig. 1). In the group without anodal polarization the 16-min period of cathodal polarization abolished retention when started as long as $2 \mathrm{hr}$ after transfer. When an 8-min period of anodal polarization was given first, however, cathodal polarization abolished retention if begun at $30 \mathrm{~min}$ (12.2 trials) but not at $1 \mathrm{hr}$ (5.4 trials). With the 16-min period, the effect of the anodal current was still greater; now cathodal current did not impair retention even when started at $30 \mathrm{~min}$ after transfer (5.6 trials). 


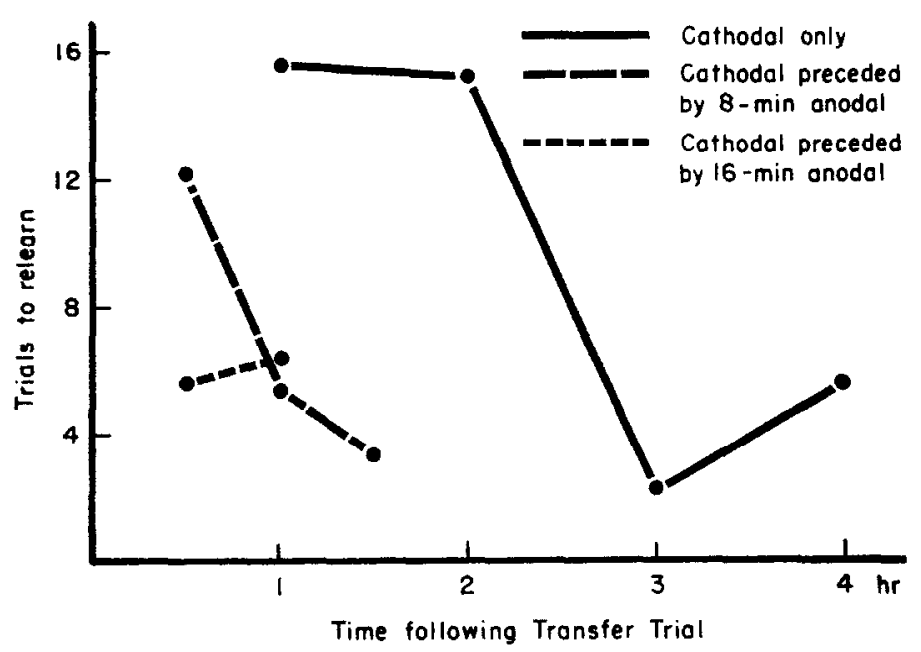

FIG. 1. The effect of a $0-, 8-$, or 16-min period of anodal polarization at $5 \mathrm{~min}$ after transfer on the length of time afterward when a $16-\mathrm{min}$ period of cathodal polarization can be applied and abolish retention. The average scores of 5 animals determine each point.

These results clearly suggest that cathodal and anodal currents have opposite effects on the same process. The parameters for the most effective surface-positive and surfacenegative currents are similar: a pulsating current is more effective than a constant current and a longer period of polarization is more effective than a short one. Further, there is also a similarity in the quantitative effect of the oppositively directed currents. For example, when transfer is followed by a 16-, but not an 8-min, period of anodal polarization consolidation is speeded enough to prevent its disruption by the immediate application of a 16-min period of cathodal polarization.

\subsection{Restarting consolidation}

This experiment considers the possibility that anodal polarization can establish the conditions necessary for consolidation. It makes use of the fact that the experiments demonstrating the slowing [2] and speeding of consolidation (Table 1) show that it is possible to considerably interfere with the consolidation process without impairing retention. The importance of this finding is to point out that consolidation can be disturbed without destroying the mechanism holding information. This suggests that the information holding mechanism may be very stable and that the effect of agents which block consolidation is not to destroy the information holding mechanism but to disturb the conditions required for its consolidation. Applying anodal polarization following such a disturbance, might be sufficient to reestablish these conditions and, therefore, restart the interrupted process.

The animals were trained and given a transfer trial. Five minutes later, cathodal polarization (to block consolidation) was started in the receiving hemisphere and continued for $8 \mathrm{~min}$; then at $1 \mathrm{hr}$ after transfer, anodal polarization (to restart consolidation) began and continued for $16 \mathrm{~min}$. The control group received only the 8 -min period of cathodal polarization. All animals were tested for retention of the learning on the following day.

The results (Table 3) show that a period of anodal polarization which follows the disrupting of consolidation by cathodal current does reestablish the consolidation process. 
The animals receiving the anodal polarization following the cathodal polarization showed significant savings in relearning (4.5 trials, $P<0.05$ ) while the control group with only cathodal polarization did not (14.8 trials).

Table 3. The effect on retention of starting a 16-min period of anodal polarization following an 8-min period of cathodal polarization or a $10-\mathrm{min}$ period of spreading depression

\begin{tabular}{llcc}
\hline & & \multicolumn{2}{c}{ Mean trials to learn } \\
\cline { 3 - 3 } Treatment & $\mathrm{N}$ & $\begin{array}{c}\text { First } \\
\text { learning }\end{array}$ & $\begin{array}{c}\text { Learning with } \\
\text { untrained hemisphere }\end{array}$ \\
\hline $\begin{array}{l}\text { Cathodal polarization then anodal } \\
\text { polarization }\end{array}$ & 6 & $16.3 \pm 7.6$ & $4.5 \pm 5.1^{*}$ \\
$\begin{array}{l}\text { Cathodal polarization only } \\
\begin{array}{l}\text { Spreading depression then anodal } \\
\text { polarization }\end{array}\end{array}$ & 6 & $11.1 \pm 5.5$ & $14.8 \pm 4.6$ \\
$\begin{array}{l}\text { Spreading depression only } \\
+ \text { Spreading depression then anodal } \\
\text { polarization }\end{array}$ & 9 & $14.0 \pm 4.6$ & $11.7 \pm 4.2$ \\
\hline Spreading depression only & 6 & $12.7 \pm 2.8$ & $7.3 \pm 2.8^{*}$ \\
\hline
\end{tabular}

* Significantly different from first learning $(P<0.05)$.

$\dagger$ Groups run blind.

The experiment was repeated but this time consolidation was interrupted by cortical spreading depression. In the experimental group, a 10-min period of spreading depression was started in the receiving hemisphere about $5 \mathrm{~min}$ following transfer and then at $1 \mathrm{hr}$, a 16-min period of pulsating surface-positive polarization was applied. The control group received only the 10-min period of spreading depression.

The results (Table 3 ) were the same as in the previous experiment. The animals given anodal polarization following the disturbance of consolidation showed significant savings in relearning ( 3.0 trials) but the control group did not (11.7 trials).

This experiment was also repeated blind. The results were the same (Table 3): the experimental group given anodal polarization relearned in 7.3 trials while the animals with only spreading depression took 13.2 trials $(P<0.05)$.

These results seem to show that anodal polarization can restart a consolidation process that has been interrupted by spreading depression or cathodal polarization. They also support the suggestion that these agents have their effect by disturbing conditions necessary for consolidation and not by destroying a required information holding mechanism.

\subsection{Information holding during consolidation}

The remaining experiments make use of the effects of anodal and cathodal polarization to explore further characteristics of the consolidation process. The first of these considers whether the information holding mechanism necessary for consolidation also mediates 
recall during the period of consolidation. The possibility that it does fulfill this function was tested by observing whether the learning could be recalled following the disturbance of consolidation. Since neither spreading depression nor cathodal polarization seem to destroy this holding mechanism (Table 3), it might be able to function in recall for a period of time afterward.

The animals were given a transfer trial and then 5 min later received a 4-min period of spreading depression or a $10-\mathrm{min}$ period of cathodal polarization. One to two hours later all were tested for retention.

Table 4 shows the results. The group receiving calhodal polarization showed retention (6.0 trials) but the group given spreading depression did not (13.1 trials). To control for the possibility that the cathodal polarization was simply facilitating relearning, another group was given the 10 -min period of cathodal polarization but was not given a transfer trial. Relearning in this group was not better than the original learning (16.3 trials). Another group controlled for the possibility that the slow relearning of the group given spreading depression was simply the result of inefficient cortical functioning as a result of the spreading depression. This group was given spreading depression $24 \mathrm{hr}$ after transfer (when consolidation is complete) and tested for retention 1-2 hr later. These animals showed significant savings in relearning (4.2 trials).

Table 4. The effect of cathodal polarization or spreading depression 5 min after the transfer trial on rate of relearning 1-2 $\mathrm{hr}$ later

\begin{tabular}{|c|c|c|c|c|}
\hline \multirow[b]{2}{*}{ Treatment } & \multirow[b]{2}{*}{$\mathrm{N}$} & \multirow[b]{2}{*}{$\begin{array}{l}\text { Time after } \\
\text { transfer trial }\end{array}$} & \multicolumn{2}{|c|}{ Mean trials to learn } \\
\hline & & & $\begin{array}{c}\text { First } \\
\text { learning }\end{array}$ & $\begin{array}{l}\text { Learning with } \\
\text { untrained hemisphere }\end{array}$ \\
\hline $\begin{array}{l}\text { 10-min period of cathodal } \\
\text { current }\end{array}$ & 5 & $5 \mathrm{~min}$ & $15.0 \pm 2.5$ & $6.0 \pm 3.0^{*}$ \\
\hline $\begin{array}{l}10 \text {-min period of cathodal } \\
\text { current }\end{array}$ & 4 & No transfer trial & $19.3 \pm 7.4$ & $16.3 \pm 1.2$ \\
\hline $\begin{array}{l}\text { 4-min period of spreading } \\
\text { depression }\end{array}$ & 7 & $5 \mathrm{~min}$ & $16.6+3.4$ & $13.1+4.6$ \\
\hline $\begin{array}{l}\text { 4-min period of spreading } \\
\text { depression }\end{array}$ & 6 & $24 \mathrm{hr}$ & $16.2 \pm 5.9$ & $4.2 \pm 0.7^{*}$ \\
\hline
\end{tabular}

Significantly different from first learning $(P<0.05)$

The results of the present experiments suggest that there are at least two information holding mechanisms present during the consolidation period, one allowing for recall during consolidation and the other involved in the actual consolidation process, perhaps serving as a template in the formation of the permanent retention system. The existence of separate mechanisms fulfilling the template and recall functions during consolidation is suggested primarily by the finding that spreading depression affects these differently; it disturbs the mechanism mediating recall (Table 4) but does not destroy the template necessary for consolidation (Table 3). 
As a further test of the conclusion that there are two information holding mechanisms present during consolidation, another experiment was done to see whether the lifetimes of the two mechanisms differ. The lifetime of the holding mechanism mediating recall was found by blocking consolidation with cathodal polarization and then testing at varying times afterward, to find the longest time when retention could be observed. Consolidation was interrupted by a 10-min period of polarization given at 5 min following transfer.

The results show that the lifetime of the mechanism mediating recall is at least $3 \mathrm{hr}$ (Fig. 2). The animals showed significant $(P<0.05)$ savings in relearning when tested at $3 \mathrm{hr}$ after transfer and were slightly better than those tested at $1 \mathrm{hr}$, but by $6 \mathrm{hr}$, relearning was not faster than the first learning.

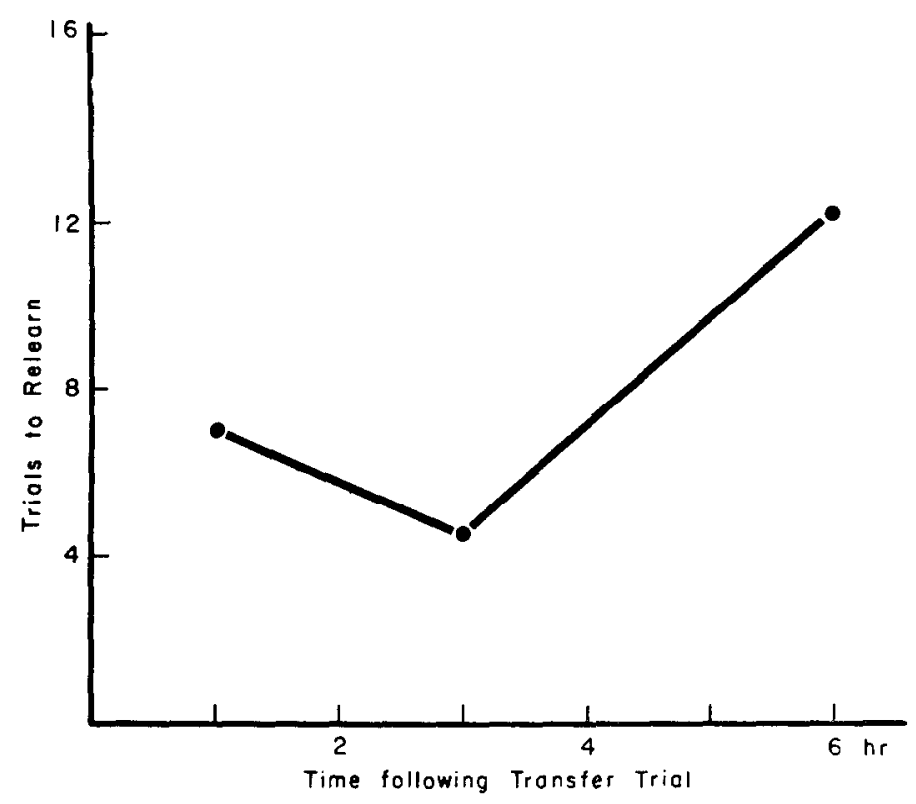

Fig. 2. The number of trials required to relearn when cathodal polarization is given at $5 \mathrm{~min}$ after the transfer trial and the animals tested at varying times afterward. The average scores of 5 animals determine each point.

The approximate lifetime of the information holding template necessary to the consolidation process was measured by first stopping the consolidation process and then reestablishing it at varying times afterward. With this method, the lifetime is at least as long as the interval between the transfer trial (when the holding mechanism is formed) and the last time when reestablishing the conditions for consolidation causes retention.

At $5 \mathrm{~min}$ following the transfer trial, all animals were given a 10-min period of spreading depression, then at varying times afterward, they were given a 16-min period of anodal polarization. The animals were tested for retention $24 \mathrm{hr}$ after the anodal polarization.

The lifetime of this holding mechanism is over $11 \mathrm{hr}$ (Fig. 3). When anodal polarization began at $11 \mathrm{hr}$ after the transfer trial, relearning was significantly $(P<0.05)$ faster than the first learning and not significantly different from a group which had anodal polarization started at $1 \mathrm{hr}$. By $17 \mathrm{hr}$ after transfer, however, anodal polarization did not result in retention. 


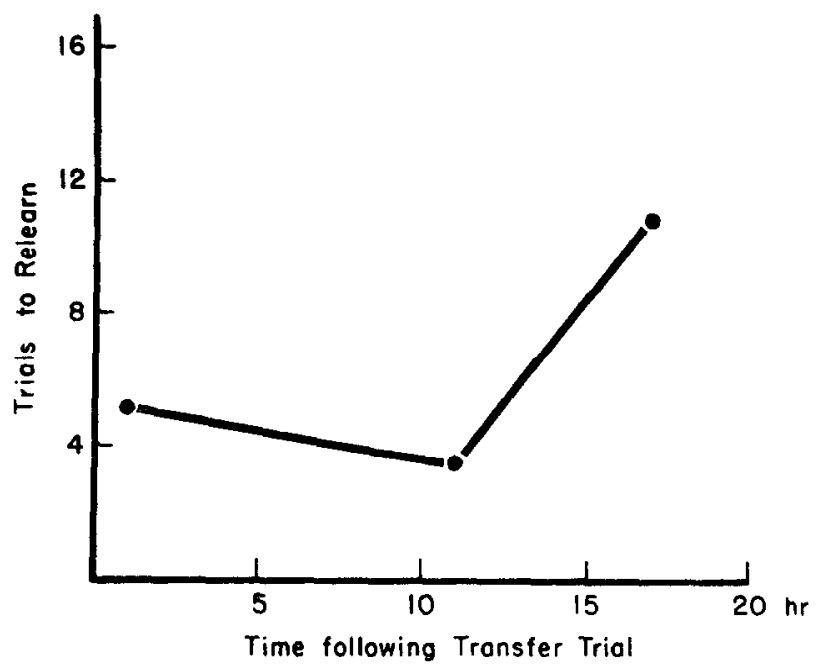

FIG. 3. The time following the transfer trial when anodal polarization can be started and still restore a consolidation process which was interrupted at $5 \mathrm{~min}$ following transfer by cathodal polarization. The average scores of 5 animals determine each point.

The difference in lifetime found for the mechanism serving as a template in consolidation and the temporary recall mechanism suggest that there are two distinct holding mechanisms performing these functions. This result is not conclusive: the procedures used to interrupt consolidation may have shortened the lifetimes, particularly that of the recall mechanism, but this difference in susceptibility to disturbance would itself suggest that two holding mechanisms are present.

\subsection{The time required for consolidation}

The length of the consolidation period has generally been taken as the time following learning when the administration of some disturbing agent prevents permanent retention of the learning. The length of the consolidation process determined in this way depends on the disturbance used and, clearly, unless that disturbance interferes with all parts of the consolidation process, the obtained consolidation time will not be correct.

The length of the consolidation period can also be defined as the interval following learning required for the permanent retention system to begin operating. The present experiment follows this definition by making use of the finding that spreading depression disturbs recall when given at $5 \mathrm{~min}$ after transfer but not at $24 \mathrm{hr}$ (Table 4). This finding suggests that spreading depression disrupts the temporary recall mechanism which exists during the consolidation period, but that it does not interfere with recall once consolidation is complete (at $24 \mathrm{hr}$ ) and the permanent retention system is operating. The length of the consolidation period can, therefore, be measured by observing the longest time following learning (transfer) when a period of spreading depression sufficient to block the temporary recall mechanism also causes a temporary loss of recall. When this period of spreading depression no longer interferes with recall of the learning, the permanent retention system is functioning and consolidation is complete. 
The animals were all given a transfer trial and then at varying times afterward were given a 4-min period of spreading depression. The animals were then tested 1-2 hr later for retention of the learning.

The length of the consolidation period determined in this way is greater than $5 \mathrm{hr}$ (Fig. 4). When the animals were given spreading depression at $5 \mathrm{hr}$ relearning (15.5 trials) was not better than the original learning, nor was it significantly different from a group which received spreading depression at $5 \mathrm{~min}$ after transfer (12.0 trials). When spreading depression was given at $10 \mathrm{hr}$, however, there was significant savings in relearning (6.8 trials, $P<0.05$ ).

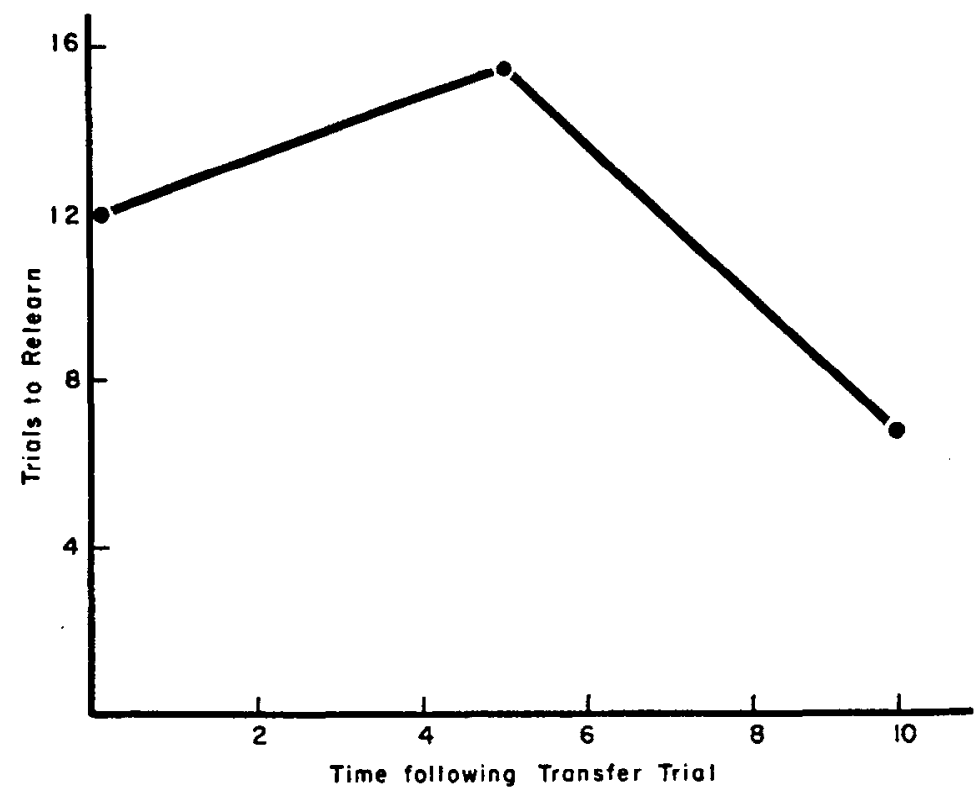

FIG. 4. The number of trials required to relearn when spreading depression is given at $5 \mathrm{~min}$, $5 \mathrm{hr}$, or $10 \mathrm{hr}$ following the transfer trial and the animals tested 1 to $2 \mathrm{hr}$ later. Each point is the average score of 5 animals.

\section{DISCUSSION}

Consolidation is clearly more complicated than has been thought. Instead of being a relatively simple process occurring in the 1 or $2 \mathrm{hr}$ after acquisition, there seems to be a sequence of processes taking over $5 \mathrm{hr}$ for completion. The present data are sufficient to divide this time into 3 periods. The first is the short transfer period, during which there is a transmission of learning from the trained to the untrained hemisphere [2]. The second is the 2 -hr period during which consolidation is easily influenced by spreading depression or polarizing currents and the third is comprised of other processes which are still unknown.

Very little is known about the 3-min period of interhemispheric transfer of learning. Spatial and temporal patterns of neural firing would seem to be necessary to represent the learning and in the receiving cortex at least two information holding mechanisms are formed, or synthesized, which temporarily retain some aspects of this pattern. One of these holding mechanisms serves as the basis of recall during the consolidation period and the other seems to be a template used in the consolidation process for forming the permanent retention system. The temporary recall mechanism is disturbed by spreading depression but not by 
cathodal polarization. Its lifetime is at least $3 \mathrm{hr}$ and probably somewhat longer. Numerous types of holding mechanisms could have these characteristics.

The template holding mechanism involved in consolidation is much more stable. It is not destroyed by a short period of spreading depression or cathodal polarization (Table 3 ) and has a lifetime of over $11 \mathrm{hr}$ (Fig. 2). The finding that this mechanism is not destroyed by spreading depression suggests that it is not a morphological synaptic change established by contiguity of firing relations of neurons $[5,7,9]$, or a maintained chemical state at the synapse. Changes of this type would be expected to be destroyed or damaged by the massive fring of spreading depression. One kind of holding mechanism that might not be affected by this kind of disruption and which could have a lifetime of over $11 \mathrm{hr}$ is an intracellular chemical change, such as a macromolecule or group of macromolecules [6].

The process that occurs during the $2 \mathrm{hr}$ following transfer is the one that has been most studied. The conditions required for this part of the consolidation process are probably established during the 3-min transfer period and seem to be related to a change in the normal potential relations in the cortex. This is suggested by the finding that the conditions necessary for this process seem to be established by a pulsating surface-positive current (Table 3) applied to the cortex and that the rate of the consolidation process is also easily increased or decreased by changing the potential relations in the cortex (Fig. 1; [2]). The effects of these polarizing currents may normally be accomplished by the slow potentials that have been observed during learning $[10,11]$; the rate of the consolidation process in that case would depend on characteristics of the learning, such as strength of reinforcement, simplicity of learning, and stage of learning.

The kind of process which would be affected by small potential changes is not clear and may have to do with properties of cortical cells which are now partly or completely unknown $[1,8,14]$. The current may have its effects directly, or indirectly through some cortical response to polarization such as the oscillations in potential observed by PURPURA

and MCMURTRY [8]. However, in either case, it seems very likely that the process is sensitive to electrical potential changes. One kind of process which would be so affected and which is consistent with most of the present findings is a simple physical chemical process such as the movement of molecules along an electrical potential gradient. Such a process could be speeded or slowed, and if blocked before completion, might have no permanent effect.

The existence of additional parts of the consolidation process after the time when spreading depression and cathodal polarization can be applied and block retention is suggested by the final experiment. It seems reasonable that some processes might occur during this time and that they might be biosynthetic processes which can not ordinarily be stopped for the long period (over $11 \mathrm{hr}$ ) during which the template holding mechanism continues to exist following learning. The main criticism of this interpretation would not seem to be that further changes after $2 \mathrm{hr}$ do not occur, but that these changes arc not caused by a temporally discrete process and, instead, are part of the long term changes that occur in stored information whereby at least part of it slowly becomes more resistant to any disturbance of neural functioning $[3,4,13]$.

\section{REFERENCES}

1. ABood, L. G., Gerard, R. W. and OCHS, S. Electrical stimulation of metabolism of homogenates and particulates. Am. J. Physiol 171, 134-139, 1952.

2. Albert, D. J. The effect of spreading depression on the consolidation of learning. Neuropsychologia 4, 49-64, 1966. 
3. Braun, H. W. and Patton, R. A. Habit reversal after electroshock convulsions as a function of the difficulty of the task. J. comp. physiol. Psychol. 43, 252-263, 1950.

4. Flexner, J. B., Flexner, L. B. and Stellar, E. Memory in mice as affected by intracerebral puromycin. Science, N.Y. 141, 57-59, 1963.

5. HғRB, D. O. The Organization of Behaviar. Wiley, New York, 1949.

6. McConnell, J. V., Jacobson, R. and Humphrjes, B. M. The effects of injection of conditionedplanaria on the response level of naive planaria. Worm Runner's Digest 3, 41-47, 1961.

7. MiLner, P. M. Learning in neural systems. In Self-Organizing Systems. Yovits, M. C. (Editor), pp. 190-200, Pergamon Press, New York, 1959.

8. Purpura, D. P. and McMurtry, J. G. Effects of transcortical polarization on intracellular potentials and evoked responses. Fedn Proc. Fedn Am. Socs exp. Biol. 23, 209, 1964.

9. RANK, J. B. Synaptic "learning" due to electroosmosis: A theory. Science, N. Y. 144, 187-189, 1964.

10. Rusinov, V. A. The problem of stationary excitation and changes in the steady potential in the cerebral cortex in conditions of the dominant focus during conditioned reflex formation. Pavlov (English translation, Elsevier, Amsterdam) 11, 6-19, 1961.

11. Rusinov, V. S. Electrophysiological studies during the formation of a temporary connection. Proc. Internat. Union Physiol. Sci., XXII Internat. Congress, Vol. 1, pp. 882-887, 1962.

12. Rusinov, V. S. Electrophysiological investigations during the formation of temporary connections. Electroenceph. clin. Neurophysiol. 15, 1061, 1963.

13. Russell, W. R. and Nathan, P. W. Traumatic amnesia. Brain 69, 280-300, 1946.

14. Strumwasser, F. and Rosenthal, S. Prolonged and patterned direct extracellular stimulation of single neurons. Am. J. Physiol. 198, 405-413, 1960.

Résumé-On a étudiè la consolidation d'une réponse d'évitement transférée d'un hémisphère à l'autre. Il semble que l'on puisse aisément modifier les conditions de consolidation par des courants polarisants. Un courant pulsatoire surface positive, que l'on applique au cortex médian, accèlère la consolidation et, lorsqu'on l'applique à la suite du trouble de la consolidation produit par la dépression extensive ou par polarisation cathodique, il fait redémarrer le processus interrompu. Ces données suggèrent que la polarisation anodique peut augmenter les conditions nécessaires à la consolidation et, lorsqu'on l'applique à la suite du trouble de ces conditions, elle peut les réétablir. D'autres expériences suggèrent qu'il y a un mécanisme spécial pour retenir l'information et qui sert de médiateur dans le processus de rétention pendant la période de consolidation, celui-ci étant distinct du mécanisme de rétention qui sert de base de départ pour la formation du système de rétention permanent. Finalement, on a cherché une nouvelle méthode d'extinction de la durée de la période de consolidation et les résultats suggèrent que le temps nécessaire à la consolidation est plus long que l'on pouvait penser à partir d'autres méthodes.

Zusammenfassung-Es wurde der Lernprozess einer Vermeidensreaktion, die durch interhemisphärischen Einfluss ausgelöst wurde, geprüft. Durch polarisierende Ströme schien die Fixierung von Lernstoff an stärksten beeinflussbar. Oberflächenpositive Stromstösse im Bereich der medialen Cortexregion waren geeignet, den Lernvorgang zu beschleunigen. Wenn man solche Stromstösse nach einer vorher künstlich gestörten Aufnahmefähigkeit infolge einer diffusen corticalen Amplitudensenkung oder durch Kathodenpolarisation anwandte, gelang es, den vorher unterbrochenen Prozess wieder in Gang zu setzen. Andere Experimente sprachen dafür, dass cs zweierlei Mechanismen gibt, die beim Erlernen bestimmter Aufgaben in Funktion treten. Eine spezielle Einrichtung zum Speichern einer Information ermöglicht das Wiedererinnern in der Zeit des Lernvorganges. Ein weiterer Mechanismus zur Fixierung von Lernstoff sorgt wie eine Schablone ganz allgemein für die Ausbildung eines permanenten mnestischen Systems. Bei einer nach neuen Methoden gemessenen Zeitperiode, die man für einen Lernvorgang benötigt, stellte sich heraus, dass man zum Lernen mehr Zeit braucht als man bisher aufgrund anders angelegter Prüfmethoden anzunehmen geneigt war. 